\title{
Model Time-Cost Trade-Off pada Pekerjaan Tangga Beton Di Banda Aceh
}

\author{
T. Muhammad Fachrul Rozie ${ }^{1}$ Fachrurrazi $^{2}$ Cut Zukhrina Oktaviani $^{3}$ \\ ${ }^{1}$ Mahasiswa, Jurusan Teknik Sipil, Universitas Syiah Kuala, Banda Aceh 23111, Indonesia \\ ${ }^{2,3}$ Dosen, jurusan Teknik Sipil, Universitas Syiah Kuala, Banda Aceh 23111, Indonesia. \\ Email: tmfrzio@gmail.com
}

\begin{abstract}
The construction project is very dependent on the project management process, both costs and time. In the implementation process, the service provider must complete one job before doing the next work. Addressing this problem requires a method that is accelerated. The purpose of this study is to do time-cost trade-off modeling. The model wa devoloped from respondent's perceptions through filling out questionnaires and RAB data. Respondents in study ware directors, estimators and project manager at construction companies domiciled in Banda Aceh. The results showed that ladder work can be broken down into formwork, cleaning and casting. Based oo sub-activities, ladder work can be accelerated from the normal duration of the projectwith the maximum additional cost arisisng from the acceleration of the duration of the ladder work is Rp. 14.109.984,07 (22,13\% of normal costs), the maximum additional cost incurred due to the acceleration of the duration of the casting work is Rp. 12.144.740,00 ((18,78\% of normal costs) and the maximum additional cost incurred due to the acceleration of the duration of the formwork work is Rp. 12.331.359,00 $(19,64 \%$ of normal costs). Additional costs per day vary for work items on the stairs because the time-cost trade-off model is non-linear.
\end{abstract}

Keyword: Time-Cost Trade-Off, normal duration, normal costs, cost of crashing stair works.

\begin{abstract}
Abstrak
Pelaksanaan proyek konstruksi sangat tergantung dengan proses manajemen proyek, baik biaya maupun waktu. Pada proses pelaksanaannya, penyedia jasa harus menyelesaikan satu pekerjaan sebelum mengerjakan pekerjaan selanjutnya. Mengatasi masalah tersebut memerlukan suatu cara yaitu dilakukan percepatan. Tujuan dari penelitian ini adalah melakukan pemodelan time-cost trade-off. Model tersebut dikembangkan dari persepsi responden melalui pengisian kuesioner dan data RAB. Responden dalam penelitian ini adalah direktur, estimator dan manajer proyek pada perusahaan konstruksi yang berdomisili di Banda Aceh. Hasil penelitian menunjukkan bahwa pekerjaan tangga dapat dipecah menjadi sub-aktifitas bekisting, pembesian dan pengecoran. Berdasarkan sub-aktifitas pekerjaan tangga dapat dipercepat dari durasi normal proyek dengan biaya tambahan maksimum yang timbul akibat percepatan durasi pada pekerjaan pengecoran tangga adalah Rp. 14.109.984,07 (22,13\% dari biaya normal), biaya tambahan maksimum yang timbul akibat percepatan durasi pada pekerjaan pembesian tangga adalah Rp. 12.144.740,00 (18,78\% dari biaya normal) dan biaya tambahan maksimum yang timbul akibat percepatan durasi pada pekerjaan bekisting tangga adalah Rp. 12.331.359,00 (19,64\% dari biaya normal). Biaya tambahan per hari berbeda-beda untuk item pekerjaan pada tangga karena model time-cost trade-off berupa non-linear.
\end{abstract}

Kata Kunci: Time-Cost Trade-Off, durasi normal, biaya normal, biaya crash pekerjaan tangga.

\section{PENDAHULUAN}

Proyek konstruksi merupakan rangkaian mekanisme pekerjaan yang saling bergantung antara yang satu dengan yang lainnya. Pada pembangunan proyek konstruksi berbagai hal dapat terjadi yang dapat menyebabkan bertambahnya waktu pelaksanaan dan biaya pelaksanaan. Faktor biaya, waktu dan kualitas membentuk suatu hubungan yang saling bergantung serta berpengaruh sangat kuat karena hal tersebut sangat menentukan keberhasilan suatu proyek.

Keberhasilan suatu proyek dapat dinilai dari penyedia jasa dalam mengambil keputusan di lapangan. Keputusan tersebut dapat berupa komunikasi dengan tenaga kerja, menentukan bahan dan material, estimasi biaya dan melakukan percepatan jika terjadi beberapa hal yang dapat menyebabkan harus dilakukan percepatan. Seringkali di lapangan penyedia jasa melakukan percepatan karena ingin menyelesaikan proyek lebih cepat dari durasi normalnya atau tepat waktu sebelum terjadi kendala yang dapat menyebabkan terlambat dalam penyelesaiannya.

Macam-macam model dari metode percepatan dapat digunakan oleh penyedia jasa, termasuk didalamnya memodelkan percepatan dengan metode time-cost trade-off..

\section{TINJAUAN KEPUSTAKAAN}

\subsection{Proyek dan Manajeman Proyek}


Santosa[1] menyebutkan proyek adalah suatu rangkaian aktifitas kegiatan atau pekerjaan yang saling berkaitan untuk mencapai suatu hasil tertentu dan dilakukan dalam periode waktu yang telah ditentukan atau ditetapkan. Sebuah proyek memiliki beberapa karakteristik penting yang terkandung di dalamnya yaitu : sementara (temporary), unik, dan progressive elaboration.

Manajemen proyek adalah tahap aplikasi pengetahuan (knowledges), keterampilan (skills), alat (tools) dan teknik (techniques) dalam aktifitas-aktifitas proyek untuk memenuhi kebutuhan-kebutuhan proyek.

\subsection{Durasi Proyek}

Dannyanti[2] menyebutkan durasi proyek adalah jumlah waktu yang diperlukan untuk menyelesaikan seluruh pekerjaan proyek. Volume pekerjaan, metode kerja, keadaan lapangan, serta keterampilan tenaga kerja dalam pelaksanaan proyek secara analitif adalah faktor yang berpengaruh dalam menentukan durasi pekerjaan. Rumus untuk menghitung durasi suatu pekerjaan yaitu :

Durasi pekerjaan $=\frac{\text { Volume pekerjaan }}{J \text { lh Tenaga Kerja } \times \text { Produktivitas }}$

\subsection{Biaya Proyek}

Mela[3] menyebutkan sumber daya antara lain tenaga kerja, material, metode dan peralatan diperlukan suatu proyek selama masa konstruksi. Kebutuhan tersebut dapat mempengaruhi biaya dan pendapatan proyek. Biaya di atas dapat berupa biaya langsung dan biaya tidak langsung.

\subsubsection{Biaya langsung}

Rani[4] menyebutkan biaya yang timbul dan berhubungan langsung dengan aktivitas proyek yang sedang dikerjakan disebut biaya langsung. Biaya langsung antara lain:

a. Biaya Bahan dan Material

Bahan atau material yang akan dipakai harus dihitung secara cermat kuantitasnya dengan telah memperhitungkan material hilang. Biaya material untuk satu tempat dengan tempat lain mungkin berbeda hal ini dipengaruhi oleh kelangkaan material, biaya transportasi dan stock material.

b. Biaya Upah

Biaya upah tenaga kerja bervariasi dan tergantung terhadap keahlian dan standart gaji dimana proyek tersebut berada. Upah pekerja ini termasuk biaya tanggungan kesehatan dan asuransi kecelakaan kerja. Lokasi proyekdimana biaya hidup tinggi maka standart gajinya juga tinggi. Untuk daerah yang cukup sulit mendapatkan tenaga kerja yang memiliki keahlian yang diharapkan, maka sangatlah mungkin untuk mendatangkan tenaga kerja dari daerah lain yang mana akan menambah biaya mobilitas pekerja dan biaya penginapan pekerja yang cukup besar.

c. Biaya Alat

Untuk peralatan umum yang biasa digunakan perlu dipertimbangkan untuk menyewa atau membeli alat tersebut. Karena dengan suatu analisa dan pertimbangan yang tepat dapat menekan biaya peralatan.

d. Biaya Sub-Kontrakor

Biaya ini diperlukan bila ada bagian pekerjaan diserahkan/dikerjakan oleh sub-kontraktor. Sub-kontraktor ini bertanggung jawab dan dibayar oleh kontraktor utama

\subsubsection{Biaya tidak langsung}

Rani[4] menyebutkan biaya yang diperlukan untuk setiap kegiatan proyek, tetapi tidak berhubungan langsung dengan kegiatan yang bersangkutan dan dihitung pada awal proyek sampai akhir proyek disebut biaya tidak langsung. Biaya tidak langsung tersebut antara lain:

a. Biaya Overhead

Biaya Overhead adalah biaya-biaya operasional yang menunjang pelaksanaan pekerjaan selama proyek berlangsung, yang meliputi :

1. Fasilitas sementara

2. Operasional petugas satpam

3. Biaya untuk K3 (Kesehatan dan Keselamatan Kerja)

b. Gaji Pegawai

Termasuk dalam unsur biaya ini adalah gaji maupun honor pegawai/ karyawan tetap dan tidak tetap yang terlibat maupun tidak terlibat dalam proyek yang dibebankan dalam pembiayaan proyek tersebut.

c. Biaya Tak Terduga

Biaya tak terduga adalah biaya untuk kejadiankejadian yang mungkin bisa terjadi, mungkin tidak.

d. Keuntungan

Keuntungan kontraktor yang direkomendasikan dalam kontrak kerja pada umumnya $10 \%$ selain itu juga tergantung besarnya resiko pekerjaan tersebut, semakin besar resikonya maka akan semakin besar pula propit yang ditetapkan. Bagi kontraktor propit sangat dipengaruhi oleh seberapa besar efesiensi yang dapat dilakukan kontraktor yang bersangkutan dengan baik mengurangi kualitas, spesifikasi dan waktu pelaksanaan proyek.

\subsection{Model Time-Cost Trade-Off}

Biswas, Karmakera, dan Biswas[6] menyebutkan bahwa time-cost trade-off adalah mengurangi durasi proyek asli yang diperoleh dari analisis jalur kritis untuk memenuhi tenggat waktu tertentu dengan biaya langsung dan tidak langsung minimum proyek. 
Ebeltagi[7] menyebutkan ada tiga jenis model time-cost trade-off untuk suatu kegiatan yaitu linier, non-linier dan diskret. Model Time-Cost Trade-Off merupakan model yang berisi parameter Normal Duration, Crash Duration, Normal Cost, Crash Cost dan Cost Slope.

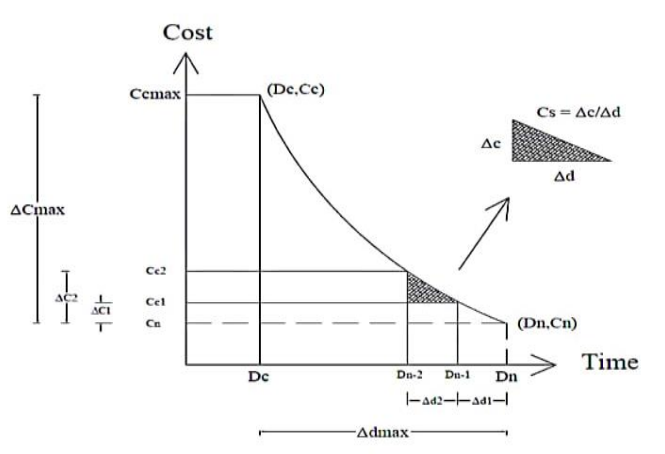

\section{Gambar 1 Ilustrasi model non-linear time-cost trade-off untuk suatu kegiatan} Sumber : Fachrurrazi[8]

\subsubsection{Normal Duration}

Normal duration adalah durasi yang dibutuhkan untuk menyelesaikan suatu kegiatan dengan sumber daya normal yang ada tanpa adanya biaya tambahan dari dalam proyek.

\subsubsection{Crash Duration}

Crash duration adalah durasi yang akan dibutuhkan oleh suatu proyek dalam usahanya untuk mempercepat durasi bagi suatu proyek sehingga durasinya lebih pendek dari normal duration.

\subsubsection{Normal Cost}

Normal Cost merupakan biaya yang dikeluarkan dengan penyelesaian proyek dalam waktu normal.

$$
C n=\frac{\text { Biaya pekerjaan }}{\text { Durasi pekerjaan }}
$$

\subsubsection{Crash Cost}

Crash Cost merupakan biaya yang digunakan untuk melaksanakan aktivitas tersebut dalam jangka waktu sebesar durasi percepatannya. Anas[5] menyebutkan rumus untuk menghitung crash cost adalah sebagai berikut :

$C c=\left(1+\% \overline{\Delta c}_{\max }\right) C n$

\subsubsection{Cost Slope}

Mela[4] menyebutkan dari kurva waktu biaya suatu kegiatan, dapat diketahui berapa slope atau sudut kemiringannya, sehingga bisa dihitung berapa besar biaya untuk mempersingkat waktu satu hari. Cost slope (Cs) adalah penambahan biaya langsung (direct cost) untuk mempercepat suatu aktivitas per satuan waktu. Rumus cost slope adalah sebagai berikut :

$C s=\frac{C c-C n}{D n-D c}$

\section{METODOLOGI PENELITIAN}

Penelitian ini dilakukan pada perusahaanperusahaan konstruksi yang berada di Banda Aceh. Data primer yang digunakan berupa kuesioner yang berisikan pertanyaan dan pandangan mengenai konsep percepatan durasi dalam proyek konstruksi, penggambaran pengaruh hubungan percepatan durasi proyek terhadap peningkatan biaya. Sedangkan data sekunder berisikan volume, biaya normal dan durasi normal.

Proses pengolahatan data dilakukan dengan cara merakapitulasi data primer dan data sekunder, kemudian data primer diuji validasi dan reabilitasinya. Sedangkan data sekunder dianalisis untuk menghasilkan model time-cost trade-off.

Berikut ini adalah tahapan-tahapan untuk menghasilkan model time-cost trade-off, yaitu :

1. Mengasumsikan normal duration aktivitas pekerjaan ke 10 hari uintuk menyeragamkan data dan membuat model yang lebih umum.

2. Menormalisasikan normal cost ke durasi acuan dengan menggunakan rumus 2).

3. Crash duration adalah durasi pekerjaan setelah dilakukan percepatan.

4. Menentukan nilai crash cost dengan menggunakan rumus 3 ).

5. Dihasilkan nilai cost slope dari rumus 4).

\section{HASIL DAN PEMBAHASAN}

\subsection{Hasil}

Pada hasil penelitian ini dikemukakan model time-cost trade-off pada tangga beton bangunan gedung di Banda Aceh dari data yang diperoleh.

\subsubsection{Karakteristik Responden}

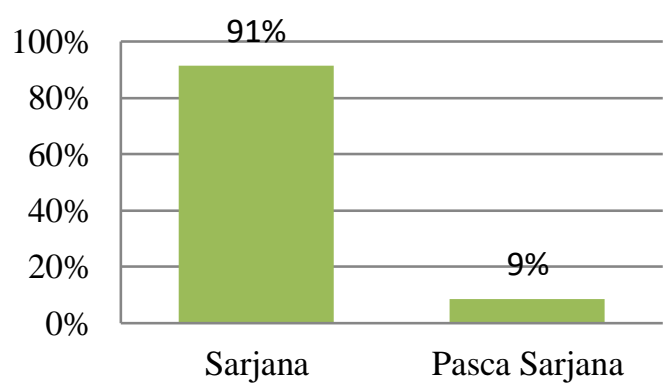

Gambar 2 Karakteristik responden berdasarkan pendidikan terakhir 


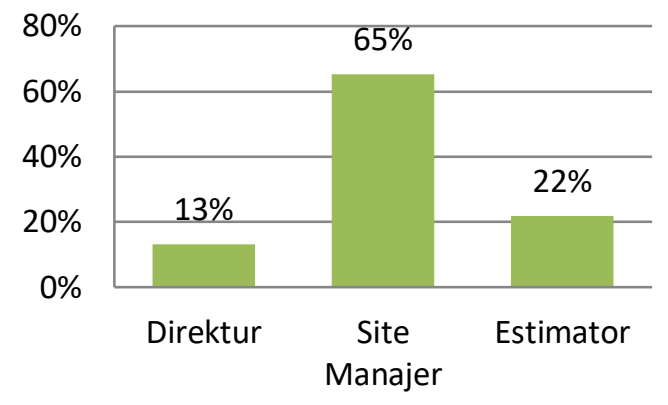

Gambar 3 Karakteristik responden berdasarkan jabatan responden

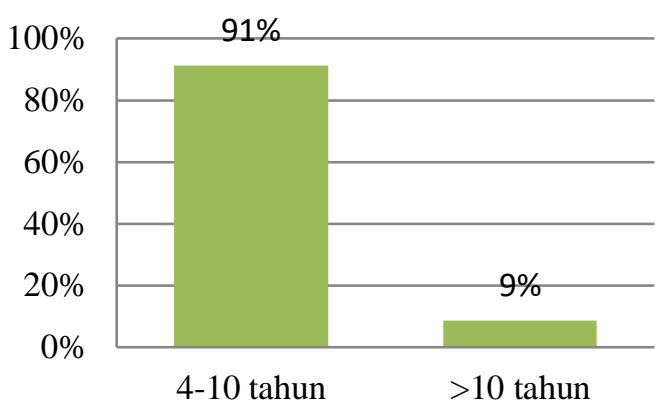

Gambar 4 Karakteristik responden berdasarkan pengalaman kerja

\subsubsection{Model Time-Cost Trade-Off}

1. Normal duration

Menyelesaikan pekerjaan dalam kondisi normal, tiap responden memiliki durasi yang berbeda-beda tergantung pada produksi responden tersebut. Dalam analisis percepatan, durasi normal ditentukan 10 hari. Hal ini dikarenakan pekerjaan tersebut harus dipercepat per harinya hingga mencapai Dc.

2. Normal cost

Analisa normal cost dihitung dengan menggunakan persamaan 2). Resume hasil dapat dilihat pada tabel 1 untuk model dan tabel 2 untuk validasi model.

Tabel 1 Resume hasil $C n / 10$ hari pekerjaan tangga untuk model

\begin{tabular}{clrcc}
\hline No & Pekerjaan & \multicolumn{1}{c}{ Volume } & Satuan & Normal Cost (Rp) \\
\hline 1 & Bekisting & 73,30 & $\mathrm{M}^{2}$ & $\mathrm{Rp} \mathrm{23.461.793,89}$ \\
2 & Pembesian & 1389,96 & $\mathrm{Kg}$ & $\mathrm{Rp} 43.552 .694,34$ \\
3 & Pengecoran & 13,94 & $\mathrm{M}^{3}$ & $\mathrm{Rp} 45.149 .063,32$ \\
\hline
\end{tabular}

Tabel 2 Resume hasil $\mathrm{Cn} / 10$ hari pekerjaan tangga untuk validasi model

\begin{tabular}{clrcc}
\hline No & Pekerjaan & Volume & Satuan & Normal Cost (Rp) \\
\hline 1 & Bekisting & 25,56 & $\mathrm{M}^{2}$ & Rp 21.052.814,33 \\
2 & Pembesian & 613,15 & Kg & Rp 36.137.308,21 \\
3 & Pengecoran & 3,77 & $\mathrm{M}^{3}$ & Rp 25.967.720,45 \\
\hline
\end{tabular}

\section{Crash Duration}

Tabel 3 Resume hasil rata-rata Dc pekerjaan tangga

\begin{tabular}{llcc}
\hline No & Item pekerjaan & Dn (Hari) & Dc (Hari) \\
\hline 1 & Pengecoran & 10 & 1 \\
2 & Pembesian & 10 & 3 \\
3 & Bekisting & 10 & 3 \\
\hline
\end{tabular}

Nilai crash duration diperoleh dari kuisioner yang telah terkumpul dan dianalisa untuk mendapatkan nilai rata-rata dari jawaban responden. Resume hasil rata-rata crash duration dapat dilihat pada Tabel 3.

4. Crash cost

Menghitung nilai crash cost perlu diketahui durasi maksimum yang dapat dipercepat ( $\Delta$ dmax). Resume hasil rata-rata $\Delta$ dmax dan $\Delta$ cmax pekerjaan tangga dapat dilihat pada Tabel 4.

Tabel 4 Resume hasil rata-rata $\Delta$ dmax dan $\Delta$ cmax pekerjaan tangga

\begin{tabular}{ccccc}
\hline \multirow{2}{*}{ No } & Item pekerjaan & $\begin{array}{c}\text { Dn } \\
\text { (Hari) }\end{array}$ & $\begin{array}{c}\Delta \text { dmax } \\
\text { (Hari) }\end{array}$ & $\begin{array}{c}\Delta \text { cmax } \\
(\%)\end{array}$ \\
\hline 1 & Pengecoran & 10 & 9 & 22,13 \\
2 & Pembesian & 10 & 7 & 18,78 \\
3 & Bekisting & 10 & 7 & 19,64 \\
\hline
\end{tabular}

Dari Tabel 4 dapat dilihat nilai $\Delta$ dmax dan $\Delta$ cmax untuk pekerjaan tangga. Nilai crash cost dapat dihitung menggunakan rumus 3 ).

Tabel 5 Resume hasil nilai Cc pekerjaan tangga

\begin{tabular}{clccc}
\hline No & Item pekerjaan & $\begin{array}{c}\Delta \text { cmax } \\
(\%)\end{array}$ & $\begin{array}{c}C n \\
(\mathrm{Rp})\end{array}$ & $\begin{array}{c}C c \\
(\mathrm{Rp})\end{array}$ \\
\hline 1 & Pengecoran & 22,13 & Rp. 45.149.063,32 & Rp. 55.142.056,00 \\
2 & Pembesian & 18,78 & Rp. 43.641.786,86 & Rp. 51.836.744,61 \\
3 & Bekisting & 19,64 & Rp. 23.461.793,89 & Rp. 28.070.732,96 \\
\hline
\end{tabular}

5. Pemodelan

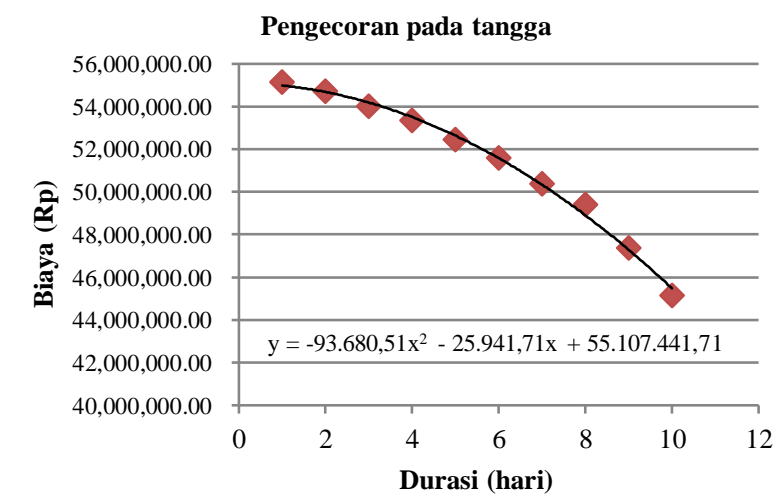

Gambar 5 Model time-cost trade-off pengecoran pekerjaan tangga 
ISSN 2685-0605

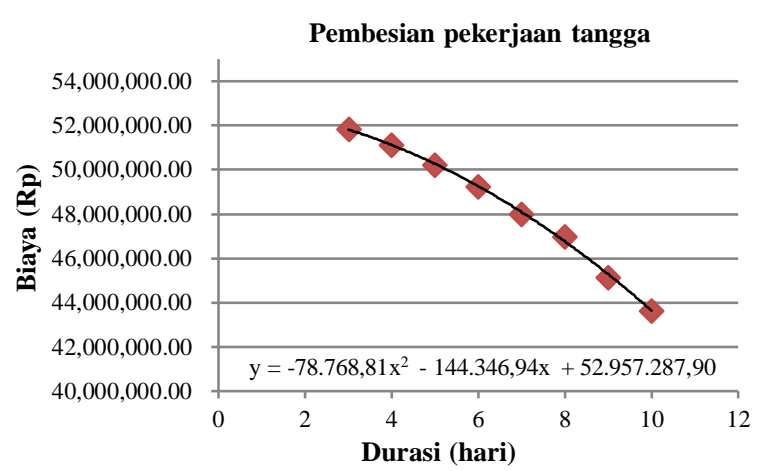

Gambar 6 Model time-cost trade-off pembesian pekerjaan tangga

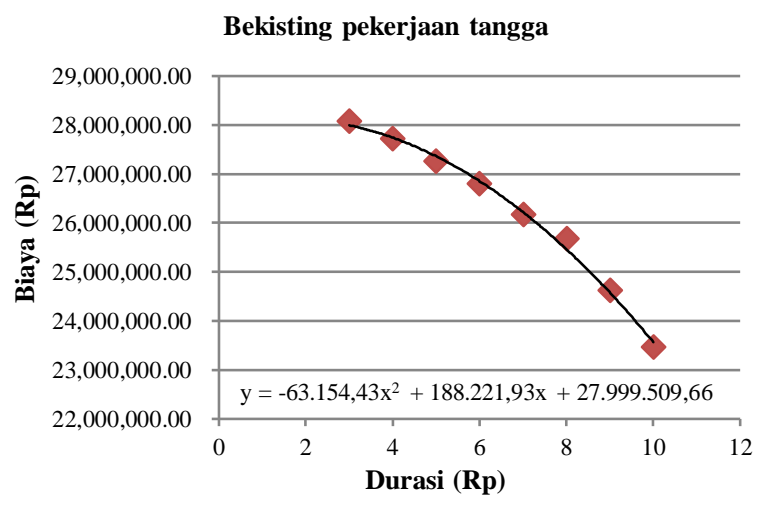

Gambar 7 Model time-cost trade-off bekisitng pekerjaan tangga

6. Cost slope

Menghitung nilai cost slope digunakan persamaan 4). Hasil perhitungan nilai cost slope dapat dilihat pada Tabel 6, Tabel 7 dan Tabel 8 berikut.

Tabel 6 Nilai cost slope dengan Dn 10 hari pekerjaan pengecoran tangga

\begin{tabular}{ccccc}
\hline $\begin{array}{c}\text { Dn } \\
\text { (Hari) }\end{array}$ & $\begin{array}{c}\text { Dc } \\
(\text { Hari })\end{array}$ & $\begin{array}{c}C n \\
(\mathrm{Rp})\end{array}$ & $\begin{array}{c}C c \\
(\mathrm{Rp})\end{array}$ & $\begin{array}{c}C s \\
(\mathrm{Rp})\end{array}$ \\
\hline$(1)$ & $(2)$ & $(3)$ & $(4)$ & $(5)=4-3 / 1-2$ \\
\hline 10 & 10 & $45.149 .063,32$ & $45.149 .063,32$ & \\
10 & 9 & $45.149 .063,32$ & $47.381 .433,67$ & $2.232 .370,35$ \\
10 & 8 & $45.149 .063,32$ & $49.403 .108,39$ & $2.127 .022,54$ \\
10 & 7 & $45.149 .063,32$ & $50.366 .288,41$ & $1.739 .075,03$ \\
10 & 6 & $45.149 .063,32$ & $51.580 .296,56$ & $1.607 .808,31$ \\
10 & 5 & $45.149 .063,32$ & $52.458 .195,01$ & $1.461 .826,34$ \\
10 & 4 & $45.149 .063,32$ & $53.346 .126,59$ & $1.366 .177,21$ \\
10 & 3 & $45.149 .063,32$ & $54.018 .345,98$ & $1.267 .040,38$ \\
10 & 2 & $45.149 .063,32$ & $54.735 .714,43$ & $1.198 .331,39$ \\
10 & 1 & $45.149 .063,32$ & $55.142 .056,00$ & $1.110 .332,52$ \\
\hline
\end{tabular}

Tabel 7 Nilai cost slope dengan Dn 10 hari pekerjaan pembesian tangga

\begin{tabular}{ccccc}
\hline $\begin{array}{c}\text { Dn } \\
\text { (hari) }\end{array}$ & $\begin{array}{c}\text { Dc } \\
\text { (hari) }\end{array}$ & $\begin{array}{c}\text { Cn } \\
(\mathrm{Rp})\end{array}$ & $\begin{array}{c}\text { Cc } \\
(\mathrm{Rp})\end{array}$ & $\begin{array}{c}\text { Cost Slope } \\
(\mathrm{Rp})\end{array}$ \\
\hline$(1)$ & $(2)$ & $(3)$ & $(4)$ & $(5)=4-3 / 1-2$ \\
\hline 10 & 10 & $43.641 .786,86$ & $43.641 .786,86$ & \\
10 & 9 & $43.641 .786,86$ & $45.154 .702,14$ & $1.512 .915,28$ \\
10 & 8 & $43.641 .786,86$ & $46.999 .779,90$ & $1.678 .996,52$ \\
10 & 7 & $43.641 .786,86$ & $47.991 .418,28$ & $1.449 .877,14$ \\
10 & 6 & $43.641 .786,86$ & $49.249 .756,47$ & $1.401 .992,40$ \\
10 & 5 & $43.641 .786,86$ & $50.219 .573,96$ & $1.315 .557,42$ \\
10 & 4 & $43.641 .786,86$ & $51.126 .353,31$ & $1.247 .427,74$ \\
10 & 3 & $43.641 .786,86$ & $51.836 .744,61$ & $1.170 .708,25$ \\
\hline
\end{tabular}

Tabel 8 Nilai cost slope dengan Dn 10 hari pekerjaan bekisting tangga

\begin{tabular}{ccccc}
\hline $\begin{array}{c}\text { Dn } \\
\text { (Hari) }\end{array}$ & $\begin{array}{c}\text { Dc } \\
(\text { Hari })\end{array}$ & $\begin{array}{c}\text { Cn } \\
(\mathrm{Rp})\end{array}$ & $\begin{array}{c}\text { Cc } \\
(\mathrm{Rp})\end{array}$ & $\begin{array}{c}\text { Cs } \\
(\mathrm{Rp})\end{array}$ \\
\hline$(1)$ & $(2)$ & $(3)$ & $(4)$ & $(5)=4-3 / 1-2$ \\
\hline 10 & 10 & $23.461 .793,89$ & $23.461 .793,89$ & \\
10 & 9 & $23.461 .793,89$ & $24.621 .849,26$ & $1.160 .055,36$ \\
10 & 8 & $23.461 .793,89$ & $25.672 .416,25$ & $1.105 .311,18$ \\
10 & 7 & $23.461 .793,89$ & $26.172 .934,52$ & $903.713,54$ \\
10 & 6 & $23.461 .793,89$ & $26.803 .796,09$ & $835.500,55$ \\
10 & 5 & $23.461 .793,89$ & $27.259 .997,64$ & $759.640,75$ \\
10 & 4 & $23.461 .793,89$ & $27.721 .412,92$ & $709.936,50$ \\
10 & 3 & $23.461 .793,89$ & $28.070 .732,96$ & $658.419,87$ \\
\hline
\end{tabular}

\subsection{Pembahasan}

Setiap data sekunder yang terkumpul memiliki biaya dan durasi yang berbeda-beda. Sehingga diperlukan durasi normal untuk menganalisis biaya normal pekerjaan. Untuk

1. Normal duration (Dn)

Penyeragamkan data biaya normal digunakan durasi acuan yaitu Dn 10 hari.

2. Normal cost $(\mathrm{Cn})$ untuk tiap pekerjaan yaitu :

- Pekerjaan pengecoran tangga : Rp 45.149.063,32

- Pekerjaan pembesian tangga : Rp 43.641.786,86

- Pekerjaan bekisting tangga : Rp 23.461.793,89

3. Crash duration (Dc) diperoleh dengan mengacu pada Dn 10 hari.

- Pekerjaan pengecoran tangga Dc $=1$ hari

- Pekerjaan pembesian tangga Dc $=3$ hari

- Pekerjaan bekisting tangga Dc $=3$ hari

4. Crash cost $(\mathrm{Cc})$ yang didapat dari analisis data yaitu :

- Pekerjaan pengecoran tangga :

$\mathrm{Cc}=\mathrm{Rp} \quad 55.142 .056,00$

- Pekerjaan pembesian tangga :

$\mathrm{Cc}=\mathrm{Rp} \quad 51.836 .744,61$

- Pekerjaan bekisting tangga $\mathrm{Cc}=\mathrm{Rp} \quad 28.070 .732,96$ 
5. Model time-cost trade-off durasi 10 hari dan tambahan biaya pada masing-masing pekerjaan.

- Pekerjaan pengecoran :

$\mathrm{y}=-93.680,51 \mathrm{x} 2-25.941,71 \mathrm{x}+55.107 .441,71$

- Pekerjaan pembesian :

$\mathrm{y}=-78.768,81 \mathrm{x} 2-144.346,94 \mathrm{x}+52.957 .287,90$

- Pekerjaan bekisting :

$y=-63.154,43 x 2+188.221,93 x+27.999 .509,66$

6. Cost Slope (Cs) yang dihasilkan dari model berbeda-beda untuk setiap pekerjaan. Nilai cost slope (Cs) yang dihasilkan adalah sebagai berikut :

- Nilai Cs pekerjaan pengecoran adalah

Dc 1 hari = Rp. 1.110.332,52

Dc 2 hari $=$ Rp. 1.198.331,39

Dc 3 hari $=$ Rp. 1.267.040,38

Dc 4 hari $=$ Rp. 1.366.177,21

Dc 5 hari $=$ Rp. 1.461.826,34

Dc 6 hari $=$ Rp. 1.607.808,31

Dc 7 hari $=$ Rp. $1.739 .075,03$

Dc 8 hari $=$ Rp. $2 \cdot 127.022,54$

Dc 9 hari $=$ Rp. 2.232.370,35

- Nilai Cs pekerjaan pembesian adalah

Dc 1 hari = Rp. $1.170 .708,25$

Dc 2 hari $=$ Rp. $1.247 .427,74$

Dc 3 hari $=$ Rp. $1.315 .557,42$

Dc 4 hari = Rp. 1.401.992,20

Dc 5 hari $=$ Rp. $1.449 .877,14$

Dc 6 hari $=$ Rp. 1.678.996,52

Dc 7 hari $=$ Rp. 1.512.915,28

- $\quad$ Nilai Cs pekerjaan bekisting adalah

Dc 1 hari $=$ Rp. $658.419,87$

Dc 2 hari $=$ Rp. $709.936,50$

Dc 3 hari $=$ Rp. $759.640,75$

Dc 4 hari $=$ Rp. $835.500,55$

Dc 5 hari $=$ Rp. $903.713,54$

Dc 6 hari $=$ Rp. $1.105 .311,18$

Dc 7 hari $=$ Rp. $1.160 .055,36$

Dari nilai cost slope (Cs) diatas dapat dilihat bahwa tambahan biaya yang timbul akibat percepatan durasi menjadi tidak tetap, karena model time-cost trade-off adalah non-linear.

\section{KESIMPULAN DAN SARAN}

Berdasarkan hasil dan pembahasan dapat diambil kesimpulan dan saran.

\subsection{Kesimpulan}

Kesimpulan yang diperoleh dari model timecost trade-off pada pekerjaan tangga beton bangunan gedung di Banda Aceh, antara lain:

1. Pengolahan data untuk model time-cost tradeoff menunjukkan adanya tambahan biaya pelaksanaan akibat percepatan durasi.
2. Model yang dihasilkan adalah persamaan nonlinear metode kuadratik dengan persamaan $\mathrm{y}=55.107 .441,71-25.941,71 \mathrm{x}-93.680,51 \mathrm{x} 2$ untuk pekerjaan pengecoran dengan persamaan $\mathrm{y}=52.957 .287,90-144.346,94 \mathrm{x}-78.768,81 \mathrm{x} 2$ pekerjaan pembesian dengan persamaan dan $y=27.999 .509,66+188.221,93 x-63.154,43 x 2$ untuk pekerjaan bekisting.

3. Pada pekerjaan pengecoran tangga dapat dilakukan percepatan sebesar $90 \%$ dari durasi normalnya, pekerjaan pembesian tangga dapat dilakukan percepatan sebesar $70 \%$ dari durasi normalnya dan pekerjaan bekisting tangga dapat dilakukan percepatan sebesar $70 \%$ dari durasi normalnya.

4. Dari model time-cost trade-off yang dihasilkan, biaya tambahan maksimum yang timbul akibat percepatan durasi pada pekerjaan pengecoran tangga adalah Rp. 14.109.984,07 (22,13\% dari biaya normal), biaya tambahan maksimum yang timbul akibat percepatan durasi pada pekerjaan pembesian tangga adalah Rp. 12.144.740,00 (18,78\% dari biaya normal) dan biaya tambahan maksimum yang timbul akibat percepatan durasi pada pekerjaan bekisting tangga adalah Rp. 12.331.359,00 (19,64\% dari biaya normal). Biaya tambahan per hari berbeda-beda untuk item pekerjaan pada tangga karena model timecost trade-off berupa non-linear.

\subsection{Saran}

1. Pada penelitian selanjutnya dapat dilakukan penelitian pada proyek yang sedang berjalan sehingga data yang diperoleh lebih akurat.

2. Penelitian selanjutnya dapat dilakukan penelitian pada jenis bangunan yang lain sehingga data yang diperoleh lebih variasi.

\section{DAFTAR PUSTAKA}

[1] Santosa, B., Manajemen Proyek Konsep \& Implementasi, Graha Ilmu, Yogyakarta, 2009.

[2] Dannyanti, E., Optimalisasi Pelaksanaan Proyek Dengan Metode PERT dan CPM Studi Kasus : Twin Tower Building Pasca Sarjana Undip , Fakultas Ekonomi, Universitas Diponegoro, Semarang. 2010.

[3] Mela, A. F., Analisis Time-Cost Trade-Off Untuk mengejar Keterlambatan Pelaksanaan Proyek Pembangunan Hotel Zodiak Lampung, Pembangunan Hotel Park In by Radisson, Pembangunan Toko Mitra Hasil Sentosa di Bandar Lampung, Fakultas Teknik, Universitas Lampung, Bandar Lampung, 2016. 
[4] Rani, I. A., Analisis Perbandingan Percepatan Pelaksanaan Pekerjaan Ditinjau dari Penambahan Jam Kerja pada Proyek Pembangunan Gedung ITERA Tahap I, Fakultas Teknik, Universitas Lampung, Bandar Lampung, 2014.

[5] Anas, C. Y., "Model Time Cost Trade Off (TCTO) pada Percepatan Durasi Proyek Konstruksi”, Fakultas Teknik, Teknik Sipil, Universitas Syiah Kuala, Banda Aceh, 2017.

[6] Biswas, S. K,, Karmakera, C. I, dan Biswas, T. K., "Time-Cost Trade-Off Analysis in a Construction Project Problem: Case Study", IJCER 06(10): 33-38, 2016.

[7] Ebeltagi, E., Lecture Notes on Construction Project Management, Mansoura University, Egypt, 2009.

[8] Fachrurrazi, Mahmudin, dan Ana, C., Y., TimeCost Trade-Off Model For Tie Beam Activity, Jurnal Teknik Sipil 7(1): 9-15, 2018. 